\title{
Association of Infantile Anorexia with Sleep Pattern and Cognitive Development of Children at Southern Region of Central Java, Indonesia
}

\author{
Nenden Nursyamsi Agustina $\mathbb{D}^{1}$, Qodri Santosa ${ }^{1}$, Nurul Afifah Munaya ${ }^{2}$ and Gema Citra Dwijayanti \\ (iD) $2{ }^{*}$ \\ ${ }^{1}$ Departement of Pediatrics, Jenderal Soedirman University, Banyumas, Indonesia \\ ${ }^{2}$ Departement of Molecular Biology, Jenderal Soedirman University, Banyumas, Indonesia \\ "Corresponding author: Departement of Molecular Biology, Jenderal Soedirman University, Banyumas, Indonesia. Tel: +62-85602000029, Email: \\ gema.dwijayanti@unsoed.ac.id
}

Received 2020 April 22; Revised 2021 April 28; Accepted 2021 May 15.

\begin{abstract}
Background: Cognitive development plays an important role in a child's life. Cognitive development and sleep patterns can interfere with the brain cell growth related to health and nutrition in children. Many children are reported to have eating difficulty in infantile anorexia. Infantile anorexia is an eating disorder during the children's period of learning ( 6 - 36 months of age). The disorder is characterized by extreme refusal of eating, deficiency of growth, and loss of typical appetite.

Objectives: This study aimed to determine the association of infantile anorexia at 12 - 36 months of age with cognitive development and sleep patterns in children.

Methods: This analytic observational study with a case-control design was conducted on the subjects divided into 40 infantile anorexia children and 40 controls. Infantile anorexia was diagnosed by a trained pediatrician. Cognitive assessment was measured by the Capute Scale test. The Brief Infant Sleep Questionnaire measured the data on children's sleep patterns. The association of infantile anorexia and children's cognitive development was analyzed by the chi-square test.

Results: The result showed a significant association between infantile anorexia and children's cognitive development (OR: 52.76; 95\% CI: 6.58 - 423.0; $\mathrm{P}<0.001)$. A similar association was also observed between children's sleep patterns and infantile anorexia (OR: $4.88 ; 95 \%$ CI: 1.80 - 13.21; $\mathrm{P}<0.002)$.

Conclusions: The findings of this study demonstrated that children with infantile anorexia are more likely to have impaired cognitive development and abnormal sleep patterns.
\end{abstract}

Keywords: Capute Scale, Cognitive Development, Infantile Anorexia, Sleep Disorders, Sleep Patterns

\section{Background}

Cognitive development plays an important role in a child's life and learning. Sleep decreases the rates of response and interaction with an environment that can be reversed and occur quickly. Sleep is one of the basic human needs varying by age. The average sleep duration for neonates is approximately 14 - 15 h per day (1). Most children have normal sleep patterns; however, 15 - 30\% of children have sleep problems when they are neonates. Cognitive development and sleep patterns can interfere with brain cell growth related to health and nutrition in children $(2,3)$.

Nutrition is one of the essential concerns during childhood. Eating difficulties were reported in 25 - $40 \%$ of chil- dren (4). The dominant age group with eating difficulty is 1 - 5 years of age (58\%). A study examined $24.8 \%$ of children who refused to eat (5). Studies performed on nutrition in childhood have provided a great deal of information about eating disorders. One of the eating disorders in children is infantile anorexia. Infantile anorexia is an eating disorder during a child's period for learning (6 - 36 months of age). The disorder is characterized by the extreme refusal of eating, deficiency of growth, and loss of typical appetite $(6,7)$.

\section{Objectives}

Studies have been rarely performed on infantile anorexia in Indonesia; therefore, the present study aimed to examine the association between infantile anorexia 
with cognitive development and sleep patterns among children in a referral hospital in the southern part of Central Java, Indonesia.

\section{Methods}

This analytic observational study with a case-control design was conducted on 40 children with infantile anorexia and 40 healthy children as a comparison group. The subjects were consecutively recruited from 1900 patients who visited the Pediatric Outpatient Clinic at Prof. Dr. Margono Soekarjo Hospital during 2018 - 2019. Margono Soekarjo Hospital is an academic hospital located in the southwestern region of Central Java province, Indonesia, and a referral hospital for six districts located in the region. The inclusion criteria (case group) were children aged 12 - 36 months with feeding difficulties meeting the criteria for infantile anorexia. The subjects with a history of premature birth, low birth weight, asphyxia, and chronic diseases were excluded from the study. This study received ethical approval from the Ethics Committee of Prof. Dr. Margono Soekarjo Hospital (reference no.: 070/16642/XII/2018). All the legal guardians of the subjects gave written consent to participate in the study.

The diagnosis of infantile anorexia was made by a pediatrician based on the diagnostic classification of mental health and developmental disorders of infancy and early childhood-revised. The data were recorded in the medical records and then extracted to be analyzed in the study. The data were measured using a nominal dichotomous scale and classified under infantile anorexia and healthy. The cognitive development of the subjects was directly assessed by a trained pediatrician using the Capute scale test categorized into "normal" and "impaired". The children's sleep patterns were examined using the Brief Infant Sleep Questionnaire (BISQ) and categorized into "normal" and "abnormal". The data on age, gender, nutritional status, and maternal educational background were also collected directly to describe the characteristics of the subjects.

All the study variables were described based on their measurement scale. The categorical data were presented using absolute and relative frequencies (percentage); however, the numerical data were presented using mean and standard deviation. For the assessment of the association between dependent and independent variables, bivariate analysis was performed using the chi-square test. A P-value of less than 0.05 was considered statistically significant. The odds ratio (OR) with a 95\% confidence interval (95\% CI) was also calculated to indicate the strength of the association. The Kolmogorov-Smirnov test was used as an alternative test when the conditions for applying the chi-square test could not be fulfilled.

\section{Results}

Table 1 shows the characteristics of the study subjects. According to gender, 55\% of the patients were female children, which was higher than the percentage of the male children (45\%). In this study, 38 children had mothers with a high school diploma (47.5\%). The nutritional status of the majority of respondents was classified as good $(n=64 ; 80 \%)$ (Table 1).

\begin{tabular}{|c|c|c|}
\hline Characteristics & No. (\%) & $\operatorname{Mean} \pm \mathbf{S D}$ \\
\hline Age & & $18.91 \pm 7.69$ \\
\hline \multicolumn{3}{|l|}{ Gender } \\
\hline Male & $36(45)$ & \\
\hline Female & $44(55)$ & \\
\hline \multicolumn{3}{|l|}{ Nutritional characteristics } \\
\hline Good nutrition & $64(80.0)$ & \\
\hline Moderate malnutrition & $7(8.75)$ & \\
\hline Severe malnutrition & $9(11.25)$ & \\
\hline \multicolumn{3}{|c|}{ Maternal educational background } \\
\hline Primary school & $13(16.25)$ & \\
\hline Junior high school & $18(22.5)$ & \\
\hline High school & $38(47.5)$ & \\
\hline University & $11(13.75)$ & \\
\hline
\end{tabular}

Table 2 shows the characteristics distribution based on cognitive development value. In this study, 9 male children (11.25\%) were reported with impaired cognitive development; nevertheless, 27 male children (33.75\%) were normal. In addition, 15 female children (18.75\%) were reported with impaired cognitive development; nonetheless, 29 female children (36.25\%) were normal. The most frequent nutritional status, both in impaired and normal cognitive development, was good. The most common maternal educational background was the high school with 13 mothers (16.25\%) in children with impaired cognitive development and 25 mothers (31.25\%) in healthy children. Gender, nutritional status, and maternal education did not have a significant relationship with children's cognitive development (P>0.05).

Table 3 shows the characteristics distribution based on infantile anorexia. The results in Table 3 revealed that infantile anorexia was more frequently observed in female subjects ( $n=22 ; 27.5 \%$ ). Gender, nutritional status, and maternal education did not have a significant correlation with infantile anorexia $(\mathrm{P}>0.05)$.

Table 4 shows the characteristics distribution based on children's sleep patterns. The results of the study in 


\begin{tabular}{|c|c|c|c|c|c|c|}
\hline \multirow{2}{*}{ Variables } & \multicolumn{3}{|c|}{ Cognitive Development } & \multirow{2}{*}{ P-Value } & \multirow{2}{*}{ OR } & \multirow{2}{*}{ 95\% CI } \\
\hline & Impaired & Normal & Total & & & \\
\hline Gender & & & & 0.377 & 0.64 & $0.24-1.71$ \\
\hline Male & $9(11.25)$ & $27(33.75)$ & $36(45)$ & & & \\
\hline Female & $15(18.75)$ & $29(36.25)$ & $44(55)$ & & & \\
\hline Nutritional status (BB/U) & & & & 1.000 & & \\
\hline Good nutrition & 19 & 45 & $64(80)$ & & & \\
\hline Moderate malnutrition & 3 & 4 & $7(8.75)$ & & & \\
\hline Severe malnutrition & 2 & 7 & $9(11.25)$ & & & \\
\hline Maternal educational background & & & & 0.911 & & \\
\hline Primary school & 6 & 7 & $13(16.25)$ & & & \\
\hline Junior high school & 4 & 14 & $18(22.5)$ & & & \\
\hline High school & 13 & 25 & $38(47.5)$ & & & \\
\hline University & 1 & 10 & $11(13.75)$ & & & \\
\hline
\end{tabular}

Table 4 show that 36 children (72\%) had good nutritional status and abnormal sleep patterns. The results of the Kolmogorov-Smirnov test showed a P-value of 0.924, indicating that gender, nutritional status, and maternal education did not have a significant relationship with children's sleep patterns.

Table 5 shows the relationship between infantile anorexia and children's cognitive development. The results of the bivariate analysis in Table 5 show that there was a significant relationship between infantile anorexia and cognitive development $(\mathrm{P}=0.001)$.

Table 6 shows the relationship between children's sleep patterns and infantile anorexia. The results of the bivariate analysis in Table 6 also show that there was a significant relationship between children's sleep patterns and infantile anorexia $(\mathrm{P}=0.002)$.

\section{Discussion}

The results of Table 2 in the gender section show a higher rate of normal cognitive development in the noninfantile anorexia group than that in the infantile anorexia group, with 27 males (33.75\%) and 29 females (36.25\%) children. The results indicated that there was no significant difference $(\mathrm{P}>0.05)$ between gender, nutritional status, and maternal educational background with children's cognitive development in Prof. Dr. Margono Soekarjo Hospital. Statistically, in a study performed by Husien et al., there was no relationship between gender and developmental status (8). This result is in line with the results of a study conducted by Sinto et al. explaining that male adolescents get more frequently sick, thereby causing the possibility of developmental disorders (9).

The results of the study in Table 3 in the gender section show that infantile anorexia was more frequently observed in female children. The results of the chi-square test obtained a p-value of 1.000, indicating that there was no significant relationship between gender and infantile anorexia in children in Prof. Dr. Margono Soekarjo Hospital. The findings of the current study differed from the findings of previous studies. Powell et al. stated that male adolescents experienced more eating difficulties than female adolescents (10). This finding might be due to the fact that male adolescents were more susceptible than female adolescents (11). However, the results of the present study are similar to the results of a study conducted by Ostberg and Hagelin, indicating that female subjects have more eating difficulties than male subjects (12).

The results of the study in Table 4 in the gender section show more abnormal sleep patterns in female children ( $\mathrm{n}$ $=27 ; 54 \%$. The results of the chi-square test obtained a pvalue of 1.000. The P-value of $>0.05$ indicated that there was no significant relationship between gender and children's sleep patterns at Prof. Dr. Margono Soekarjo Hospital. The results of a study performed by Schlarb et al. (13) demonstrated that there was no relationship between children's gender and sleep disorders $(\mathrm{P}=0.561)$. This result is in contrast to the results of a study conducted by Quan et al (14), in which there were more women (56.4\%) experiencing sleep problems than men $(38.6 \% ; \mathrm{P}=0.001)$, indicating that there was a relationship between gender and sleep 


\begin{tabular}{|c|c|c|c|c|c|c|}
\hline \multirow{2}{*}{ Variables } & \multicolumn{3}{|c|}{ Infantile Anorexia } & \multirow{2}{*}{ P-Value } & \multirow{2}{*}{ OR } & \multirow{2}{*}{ 95\% CI } \\
\hline & Yes & No & Total & & & \\
\hline Gender & & & & 1.000 & 1.00 & $0.41-2.41$ \\
\hline Male & $18(22.5)$ & $18(22.5)$ & $36(45)$ & & & \\
\hline Female & $22(27.5)$ & $22(27.5)$ & $44(55)$ & & & \\
\hline Nutritional status & & & & 0.671 & & - \\
\hline Good nutrition & $29(36.25)$ & $35(43.75)$ & $64(80)$ & & & \\
\hline Moderate malnutrition & $6(7.5)$ & $1(1.25)$ & $7(8.75)$ & & & \\
\hline Severe malnutrition & $5(6.25)$ & $4(5.0)$ & $9(11.25)$ & & & \\
\hline Maternal educational background & & & & 0.187 & & - \\
\hline Primary school & $8(10.0)$ & $5(6.25)$ & $13(16.25)$ & & & \\
\hline Junior high school & $7(8.75)$ & $11(13.75)$ & $18(22.5)$ & & & \\
\hline High school & $22(27.5)$ & $16(20.0)$ & $38(47.5)$ & & & \\
\hline University & $3(3.75)$ & $8(10.0)$ & $11(13.75)$ & & & \\
\hline
\end{tabular}

${ }^{\text {a }}$ Values are expressed as No. (\%) unless otherwise indicated.

\begin{tabular}{|c|c|c|c|c|c|c|}
\hline \multirow{2}{*}{ Variables } & \multicolumn{3}{|c|}{ Sleep Patterns } & \multirow{2}{*}{ P-Value } & \multirow{2}{*}{ OR } & \multirow{2}{*}{$95 \%$ CI } \\
\hline & Abnormal & Normal & Total & & & \\
\hline Gender & & & & 1.000 & 1.11 & $0.44-2.77$ \\
\hline Male & $23(46)$ & $13(43.3)$ & $36(45)$ & & & \\
\hline Female & $27(54)$ & $17(56.7)$ & $44(55)$ & 0.924 & & \\
\hline \multicolumn{7}{|l|}{ Nutritional status $(\mathrm{BB} / \mathrm{U})$} \\
\hline Good nutrition & $36(72)$ & $28(93.3)$ & $64(80)$ & & & \\
\hline Moderate malnutrition & $7(14)$ & $0(0)$ & $7(8.75)$ & & & \\
\hline Severe malnutrition & $7(14)$ & $2(6.7)$ & $9(11.25)$ & & & \\
\hline Maternal educational background & & & & 0.664 & & \\
\hline Primary school & $7(14)$ & $6(20.0)$ & $13(16.25)$ & & & \\
\hline Junior high school & $10(20)$ & $8(26.7)$ & $18(22.5)$ & & & \\
\hline High school & $29(58)$ & $9(30.0)$ & $38(47.5)$ & & & \\
\hline University & $4(8)$ & $7(23.3)$ & $11(13.75)$ & & & \\
\hline
\end{tabular}

${ }^{a}$ Values are expressed as No. (\%) unless otherwise indicated.

\begin{tabular}{|c|c|c|c|c|c|c|}
\hline \multirow{2}{*}{ Infantile Anorexia } & \multicolumn{3}{|c|}{ Cognitive Development } & \multirow{2}{*}{ P-Value } & \multirow{2}{*}{ OR } & \multirow{2}{*}{$\mathbf{9 5} \% \mathrm{CI}$} \\
\hline & Abnormal & Normal & Total & & & \\
\hline Yes & $23(28.7)$ & $17(21.25)$ & $40(50)$ & 0.01 & 52.76 & $6.58-423.01$ \\
\hline No & $1(1.25)$ & $39(48.7)$ & $40(50)$ & & & \\
\hline
\end{tabular}

${ }^{a}$ Values are expressed as No. (\%) unless otherwise indicated. 


\begin{tabular}{lccccc}
\hline Table 6. Relationship Between Infantile Anorexia and Children's Sleep Patterns \\
\hline \multirow{2}{*}{ Sleep Patterns } & \multicolumn{3}{c}{ Infantile Anorexia } & P-Value & OR \\
\cline { 2 - 5 } & Abnormal & Normal & Total & & 95\% CI \\
\hline Yes & $32(40)$ & $18(22.5)$ & $40(62.5)$ & & \\
No & $8(10)$ & $22(27.5)$ & $40(37.5)$ & & \\
\hline
\end{tabular}

patterns. Gender can interfere with sleep patterns after puberty. Menstrual patterns, pregnancy, and menopause can change the sleeping cycle (15).

\subsection{Nutritional Status}

The investigation of nutritional status was performed based on body weight according to age. The results of the study in Table 2 show that the most frequent nutritional status was good. As previously reported, 45 children (56.25\%) with good nutritional status had normal cognitive development; nevertheless, 19 children (23.75\%) with good nutritional status also had cognitive development disorders. The results of the Kolmogorov-Smirnov test obtained a P-value of 1.000. The p-value of $>0.05$ indicated that there was no significant relationship between the nutritional status and cognitive development of children at Prof. Dr. Margono Soekarjo Hospital. This finding is consistent with the findings of previous studies in which there was no relationship between nutritional status and child cognitive development.

At the age of 1 - 2 years, most children receive much attention regarding food from their mothers and still have breast milk; accordingly, the development included in the doubtful category was not included in the category of deviation $(16,17)$. The results of the study in Table 3 show nutritional status in children with infantile anorexia $(n=29$; $36.25 \%)$ and healthy children $(n=35 ; 43.75 \%)$. The results of the Kolmogorov-Smirnov test obtained a P-value of 0.671 . The P-value of $>0.05$ indicated that there was no significant relationship between nutritional status and infantile anorexia in children at Prof. Dr. Margono Soekarjo Hospital. The results of this study are in line with the results of a study conducted by Anzarkusuma et al., demonstrating that the average weight of respondents with eating difficulty was in the ideal or normal weight category (18).

The results of the study in Table 4 show that there was no significant relationship between the nutritional status and sleep patterns of children at Prof. Dr. Margono Soekarjo Hospital. Sleep is one of the most important factors affecting the components of mental and physical health. Various factors, such as nutritional status, can influence the quality and quantity of sleep. Based on a study conducted by Nachvak et al., there was a relationship between nutritional status and sleep patterns. The aforemen- tioned study demonstrated that the normal-weight subjects had sleeping quality three times higher than overweight or obese subjects (OR: 3; 95\% CI:1.04 - 8.63; P=0.04) (19).

Right weight and balanced nutrition cause to have good sleeping quality. Sleep deprivation is an obesity factor in developing countries. Sleep deprivation has become a concern because it has turned into a habit getting worse and continues if there is no effort to change the habit (20).

\subsection{Maternal Education}

The education levels of the mothers of children in Table 2 show that the highest level of educational attainment was mainly a high school diploma $(\mathrm{n}=38 ; 45.5 \%)$. The results of the Kolmogorov-Smirnov test obtained a P-value of 0.911 . The results indicated that there was no significant relationship between maternal education and infantile anorexia $(\mathrm{P}>0.05)$. However, the results of a study conducted by Bridges et al. on Mexican-American respondents are different from the results of this study because it was shown that the education level of mothers affected the development level of children under 5 years of age $(\mathrm{P}<0.01)$ (21).

The findings of the present study are also in line with the findings of a study conducted by Cassiano et al. on toddlers in Brazil and Italy. They proved that the sociodemographic factor affecting children's development was maternal educational level $(\mathrm{P}<0.01)$ (22). Increasing positive interaction between parents and children is a foundation for interventions given to children (23). The level of parental knowledge and education shapes the interaction between parents and children (24).

According to the results of the study in Table 322 children with anorexia (27.5\%) had mothers with a high school educational level, and 16 healthy children (20.0\%) had mothers with a high school diploma. The results of the chi-square test obtained a P-value of 0.187. The P-value of $>0.05$ indicated that there was no significant relationship between maternal education and infantile anorexia in children at Prof. Dr. Margono Soekarjo Hospital. This result is in contrast to the results of a study performed by Allen et al. indicating that the respondents with eating difficulty had mothers with a low educational level (25). High educational levels can affect the behavior of mothers in feed- 
ing children. Mothers with higher educational levels are expected to apply the knowledge that has been shared with families $(26,27)$.

The results of the study in Table 4 show that 29 children (58\%) with mothers with high school education had abnormal sleep patterns. The results of the chi-square test obtained a P-value of 0.664 . The P-value of $>0.05$ indicated that there was no significant relationship between the educational levels of mothers and sleep patterns of children at Prof. Dr. Margono Soekarjo Hospital.

Sleep disorders often occur in neonates. Sleep routines at initial development have a positive effect on sleep quality. A study conducted by Martins et al (28) assessed the impact of maternal education on the development of neonatal sleep patterns. The results of this study showed that maternal education was positively related to sleep patterns in neonates; accordingly, it can be a preventive strategy in neonatal care. The results of the present study are in contrast to the results of a study performed by Sekartini et al. They concluded that there was no significant relationship between sleep disorders with paternal and maternal educational levels, income levels, and number of children (29).

\subsection{Relationship of Children's Cognitive Development with In-} fantile Anorexia

Table 5 tabulates the results of the chi-square test (OR: 52.76; 95\% CI: 6.58-423.01; $\mathrm{P}<0.001$ ). The results indicated that infantile anorexia and cognitive development had a statistically significant relationship $(\mathrm{P}<0.05)$. The strength parameter of the OR relationship was 52.76. This finding showed that children with infantile anorexia were 52.76 times more likely to have cognitive development disorders than children with no eating disorders. The results of this study are in line with the results of a study conducted by Chatoor et al., indicating that children with infantile anorexia had lower cognitive values (30).

The relationship is supported by the opinion of Rosales et al. that food is significantly related to the body, especially at the stages of physical growth, development, and intelligence of school children (31). The number of cells in the brain decreases, and imperfections in biochemical organizations in the brain occur. This situation affects the growth and development of children. Eating disorders are focused on regulating appetite in the hypothalamus, which controls neurochemical mechanisms specifically for eating and satiety. Serotonin is considered to be involved in the pathophysiology of eating disorders, although this study is still in its developmental stage (32). Serotonin plays a role in memory, learning process, sleep pattern, mood, and appetite. Higher serotonin levels are in accordance with the levels of anxiety and obsessive behavior (33).
A study conducted by Kaye et al. (2009) reported that starvation could improve mood by lowering serotonin levels. However, when starvation continuously existed, the compensatory mechanism of the brain occurred through elevating the level of serotonin receptors. This soaring level of serotonin can cause extreme anxiety and emotional disturbance, difficult to recover without any sufficient support (34).

One of the genetic factors believed to be susceptible to eating disorders is the serotonin transporter (5-HTT) gene. A study reported that the low expression of 5-HTTLPR allele polymorphism had a relationship with anorexia (35). This has an important role in the susceptibility of subtypes or endophenotypes to eating disorders (36).

The subsequent discussion brings up other factors affecting children's cognitive impairment, one of which is iron in the blood. Iron is a nutrient that is important for children's growth, mental development, and motor and cognitive function. Iron deficiency anemia is associated with poor performance in neonates, low scores in cognitive function tests in preschool children, and low school learning achievement $(37,38)$.

Other effective factors in cognitive impairment among children are still closely related to the profile of hematology, one of which is the content of iodine in the blood. Iodine is a nutrient in thyroid hormone, which is responsible for regulating thyroid function, supporting healthy metabolism, and helping growth and development (39, 40). Iodine is also important for brain development over a period affecting neurogenesis, neuron and glial cell differentiation, myelination, neuron migration, and synaptogenesis. Iodine supplementation from mothers to children requires adequate attention. The adequate consumption of iodine can avoid cognitive impairment in children (41, 42).

\subsection{Relationship of Children's Sleep Patterns with Infantile Anorexia}

Table 6 tabulates the results of the chi-square test (OR: 4.88; 95\% CI: 1.80 - 13.21; $\mathrm{P}<0.002)$. The results indicated that there was a significant relationship between sleep patterns and infantile anorexia in children at Prof. Dr. Margono Soekarjo Hospital $(\mathrm{P}<0.05)$. This finding is in line with the findings of a study conducted by Tauman et al., indicating that the parents of children with insomnia had more frequent eating problems (26\%), compared to controls $(9 \%)(\mathrm{P}=0.001)$. The effective factors in sleep disorders are birth order, genetic factors, characteristics, personal and maternal psychological disturbance, caregiver behavior, nighttime feeding, and co-sleeping (43).

The characteristics of children have an important role in these two general conditions. It can lead to either sleep- 
ing disorders or eating difficulties. The characteristics of children can affect the daily interactions of parents and children, including interactions before bedtime and mealtime. The sensory description is one of the characteristics of children that is frequently revealed by parents and caregivers. Sensory processing is the ability to integrate information received from the body's sensory systems and form appropriate and efficient behavioral responses. Disrupted sensory processing can cause various functional problems and affect daily routines (44).

The Diagnostic Classification of Mental Health and Developmental Disorders of Infancy and Early Childhood(DC: 0 - 3) defines three types of disorders of sensory processing regulation in neonates, including hypersensitivity (i.e., excessive sensory response), hyposensitivity (i.e., lack of sensory response), and sensory seeking. Sensory difficulties mediate sleep development and eating disorders. The early sensory characteristics of children can influence parent and child interactions every day, including those occurring during sleep and mealtimes (45).

\subsection{Conclusion}

The results of this study showed that infantile anorexia has a strong association with impaired cognitive development and abnormal sleep patterns. These findings underline the importance of early and adequate management of infantile anorexia due to the possible long-term important effects on the well-being of the children.

\section{Footnotes}

Authors' Contribution: N.N.A and G.C.D developed the original idea and the protocol, abstracted and analyzed the data, and wrote the manuscript and guarantor. Q.S and N.A.M contributed to the development of the protocol, abstracted the data, and prepared the manuscript.

Conflict of Interests: There is no conflict of interest in this kind of manuscript submission.

Ethical Approval: This study received ethical approval from the Ethics Committee of Prof. Dr. Margono Soekarjo Hospital (reference no.: 070/16642/XII/2018.E).

Funding/Support: This study was funded by internal research grant from Jenderal Soedirman University, Ministry of Education, Culture, Research and Technology, Indonesia.

Informed Consent: All the legal guardians of the subjects gave written consent to participate in the study.

\section{References}

1. Tham EK, Schneider N, Broekman BF. Infant sleep and its relation with cognition and growth: A narrative review. Nat Sci Sleep. 2017;9:135-
49. doi: 10.2147/NSS.S125992. [PubMed: 28553151]. [PubMed Central: PMC5440010].

2. Gomez-Pinilla F. Brain foods: the effects of nutrients on brain function. Nat Rev Neurosci. 2008;9(7):568-78. doi: 10.1038/nrn2421. [PubMed: 18568016]. [PubMed Central: PMC2805706].

3. Fuller C, Lehman E, Hicks S, Novick MB. Bedtime use of technology and associated sleep problems in children. Glob Pediatr Health. 2017;4:2333794X17736972. doi: 10.1177/2333794X17736972. [PubMed: 29119131]. [PubMed Central: PMC5669315].

4. Sacrato L, Pellicciari A, Franzoni E. Emergent factors in eating disorders in childhood and preadolescence. Ital J Pediatr. 2010;36:49. doi: 10.1186/1824-7288-36-49. [PubMed: 20615223]. [PubMed Central: PMC2912312].

5. Soedibyo S, Mulyani RL. [Eating problems in patients: A survey from outpatients of pediatric unit]. Sari Pediatri. 2016;11(2):79. Indonesian. doi: 10.14238/sp11.2.2009.79-84.

6. Chatoor I, Ganiban J, Hirsch R, Borman-Spurrell E, Mrazek DA Maternal characteristics and toddler temperament in infantile anorexia. J Am Acad Child Adolesc Psychiatry. 2000;39(6):743-51. doi: 10.1097/00004583-200006000-00013. [PubMed: 10846309].

7. Lucarelli L, Ammaniti M, Porreca A, Simonelli A. Infantile anorexia and co-parenting: A pilot study on mother-father-child triadic interactions during feeding and play. Front Psychol.2017;8:376. doi:10.3389/fpsyg.2017.00376. [PubMed: 28367131]. [PubMed Central: PMC5355430].

8. Husien F, Ismail D, Sitaresmi MN. [Relationship between infantile anorexia and cognitive development]. Sari Pediatri. 2016;14(6):379. Indonesian. doi: 10.14238/sp14.6.2013.379-83.

9. Sinto R, Oktaria S, Astuti SL, Mirdhatillah S, Sekartini R, Wawolumaya C. [Developmental screening in 6 month - 3 years old children with Denver II Developmental Screening Test]. Sari Pediatri. 2016;9(5):348. Indonesian. doi: 10.14238/sp9.5.2008.348-53.

10. Powell FC, Farrow CV, Meyer C. Food avoidance in children. The influence of maternal feeding practices and behaviours. Appetite. 2011;57(3):683-92. doi: 10.1016/j.appet.2011.08.011. [PubMed: 21896295].

11. Mascola AJ, Bryson SW, Agras WS. Picky eating during childhood: A longitudinal study to age 11 years. Eat Behav. 2010;11(4):253-7. doi: 10.1016/j.eatbeh.2010.05.006. [PubMed: 20850060]. [PubMed Central: PMC2943861].

12. Ostberg M, Hagelin E. Feeding and sleeping problems in infancy-a follow-up at early school age. Child Care Health Dev. 2011;37(1):11-25. doi: 10.1111/j.1365-2214.2010.01141.x. [PubMed: 20666781].

13. Schlarb AA, Gulewitsch MD, Weltzer V, Ellert U, Enck P. Sleep duration and sleep problems in a representative sample of German children and adolescents. Health. 2015;7(11):1397-408. doi: 10.4236/health.2015.711154.

14. Quan SA, Li YC, Li WJ, Li Y, Jeong JY, Kim DH. Gender differences in sleep disturbance among elderly koreans: Hallym aging study. $J$ Korean Med Sci. 2016;31(11):1689-95. doi: 10.3346/jkms.2016.31.11.1689. [PubMed: 27709844]. [PubMed Central: PMC5056198].

15. Krishnan V, Collop NA. Gender differences in sleep disorders. Curr Opin Pulm Med. 2006;12(6):383-9. doi: 10.1097/01.mcp.0000245705.69440.6a. [PubMed: 17053485].

16. Acharya Y, Luke N, Haro MF, Rose W, Russell PSS, Oommen AM, et al. Nutritional status, cognitive achievement, and educational attainment of children aged 8-11 in rural South India. PLoS One. 2019;14(10). e0223001. doi: 10.1371/journal.pone.0223001. [PubMed: 31596845]. [PubMed Central: PMC6784908].

17. Gunawan G, Fadlyana E, Rusmil K. [Relationship between nutritional status and development of 1 -2 years old children]. Sari Pediatri. 2016;13(2):142. Indonesian. doi: 10.14238/sp13.2.2011.142-6.

18. Hafid F, Nasrul N. [Risk factors of stunting among children aged 623 months in jeneponto regency]. Indones J Hum Nutr. 2016;3(1):42-53. Indonesian. doi: 10.21776/ub.ijhn.2016.003.Suplemen.5. 
19. Nachvak S, Mostafai R, Moradi S, Eskandari S, Niazi P, Darbandi M. The association between nutritional status and sleep health. Int J Pharm Technol. 2016;8(2):12848-57.

20. Faizi N, Khan Z, Amir A, Azmi SA. Sleep duration and its effect on nutritional status in adolescents of Aligarh, India. S Afr J Child Health. 2015;9(1):18. doi: 10.7196/sajch.777.

21. Bridges M, Cohen SR, McGuire LW, Yamada H, Fuller B, Mireles L, et al. Bien Educado: Measuring the social behaviors of Mexican American children. Early Child Res Q. 2012;27(3):555-67. doi: 10.1016/j.ecresq.2012.01.005.

22. Cassiano RGM, Provenzi L, Linhares MBM, Gaspardo CM, Montirosso R. Maternal sociodemographic factors differentially affect the risk of behavioral problems in Brazilian and Italian preterm toddlers. Infant Behav Dev. 2018;50:165-73. doi: 10.1016/j.infbeh.2017.12.006. [PubMed: 29306797].

23. Morris AS, Robinson LR, Hays-Grudo J, Claussen AH, Hartwig SA, Treat AE. Targeting parenting in early childhood: A public health approach to improve outcomes for children living in poverty. Child Dev. 2017;88(2):388-97. doi: 10.1111/cdev.12743. [PubMed: 28138978]. [PubMed Central: PMC5345847].

24. Noble KG, Houston SM, Brito NH, Bartsch H, Kan E, Kuperman JM, et al. Family income, parental education and brain structure in children and adolescents. Nat Neurosci. 2015;18(5):773-8. doi: 10.1038/nn.3983. [PubMed: 25821911]. [PubMed Central: PMC4414816].

25. Allen KL, Gibson LY, McLean NJ, Davis EA, Byrne SM. Maternal and family factors and child eating pathology: Risk and protective relationships. J Eat Disord. 2014;2:11. doi: 10.1186/2050-2974-2-11. [PubMed: 24808944]. [PubMed Central: PMC4012547].

26. van Ansem WJ, Schrijvers CT, Rodenburg G, van de Mheen D. Maternal educational level and children's healthy eating behaviour: role of the home food environment (cross-sectional results from the INPACT study). Int J Behav Nutr Phys Act. 2014;11:113. doi:10.1186/s12966-014-01130. [PubMed: 25212228]. [PubMed Central: PMC4177694].

27. Arpini LDSB, Barbosa GC, Justo GF, Salaroli LB, Molina M. [AssociaÇÃo pntre a percepÇÃo materna do estado nutricional do filho e a qualidade da dieta de escolares]. DEMETRA: Alimentação, Nutrição \& Saúde. 2015;10(2). Portuguese. doi: 10.12957/demetra.2015.15112.

28. Martins RMA, Oliveira JRA, Salgado CCG, Marques BLS, Oliveira LCF, Oliveira GR, et al. Sleep habits in infants: The role of maternal education. Sleep Med. 2018;52:138-44. doi: 10.1016/j.sleep.2018.08.020. [PubMed: 30321821].

29. Sekartini R, Adi NP. [Sleep disorders in children under three years old in five cities of Indonesia]. Sari Pediatri. 2016;7(4):188. Indonesia. doi: 10.14238/sp7.4.2006.188-93.

30. Chatoor I, Surles J, Ganiban J, Beker L, Paez LM, Kerzner B. Failure to thrive and cognitive development in toddlers with infantile anorexia. Pediatrics. 2004;113(5):e440-7. doi: 10.1542/peds.113.5.e440. [PubMed: 15121987].

31. Rosales FJ, Reznick JS, Zeisel SH. Understanding the role of nutrition in the brain and behavioral development of toddlers and preschool children: identifying and addressing methodological barriers. Nutr Neurosci. 2009;12(5):190-202. doi: 10.1179/147683009X423454. [PubMed: 19761650]. [PubMed Central: PMC2776771].

32. Albay R, Chen A, Anderson GM, Tatevosyan M, Janusonis S. Relation- ships among body mass, brain size, gut length, and blood tryptophan and serotonin in young wild-type mice. BMC Physiol. 2009;9:4. doi: 10.1186/1472-6793-9-4. [PubMed: 19321004]. [PubMed Central: PMC2671477].

33. Gorwood P, Ades J, Bellodi L, Cellini E, Collier DA, Di Bella D, et al. The 5-HT(2A) -1438G/A polymorphism in anorexia nervosa: a combined analysis of 316 trios from six European centres. Mol Psychiatry. 2002;7(1):90-4. doi: 10.1038/sj.mp.4000938. [PubMed: 11803452].

34. Kaye WH, Fudge JL, Paulus M. New insights into symptoms and neurocircuit function of anorexia nervosa. Nat Rev Neurosci. 2009;10(8):57384. doi: 10.1038/nrn2682. [PubMed: 19603056].

35. Cooper-Brown L, Copeland S, Dailey S, Downey D, Petersen MC, Stimson $C$, et al. Feeding and swallowing dysfunction in genetic syndromes. Dev Disabil Res Rev. 2008;14(2):147-57. doi: 10.1002/ddrr.19. [PubMed: 18646013].

36. Lee Y, Lin PY. Association between serotonin transporter gene polymorphism and eating disorders: A meta-analytic study. Int JEat Disord. 2010;43(6):498-504. doi: 10.1002/eat.20732. [PubMed: 19708070].

37. Larson LM, Phiri KS, Pasricha SR. Iron and cognitive development: What is the evidence? Ann Nutr Metab. 2017;71(Suppl 3):25-38. doi: 10.1159/000480742. [PubMed: 29268256].

38. Hermoso M, Vucic V, Vollhardt C, Arsic A, Roman-Vinas B, IglesiaAltaba I, et al. The effect of iron on cognitive development and function in infants, children and adolescents: A systematic review. Ann NutrMetab. 2011;59(2-4):154-65. doi: 10.1159/000334490. [PubMed: 22142898].

39. Beydoun MA, Beydoun HA, Kitner-Triolo MH, Kaufman JS, Evans $\mathrm{MK}$, Zonderman AB. Thyroid hormones are associated with cognitive function: moderation by sex, race, and depressive symptoms. J Clin Endocrinol Metab. 2013;98(8):3470-81. doi: 10.1210/jc.2013-1813. [PubMed: 23690311]. [PubMed Central: PMC3733856].

40. Lazarus JH. Thyroid hormones and cognitive function. Expert Rev Endocrinol Metab. 2012;7(4):365-7. doi: 10.1586/eem.12.27. [PubMed: 30754164].

41. Choudhry $\mathrm{H}$, Nasrullah $\mathrm{M}$. Iodine consumption and cognitive performance: Confirmation of adequate consumption. Food Sci Nutr. 2018;6(6):1341-51. doi: 10.1002/fsn3.694. [PubMed: 30258574]. [PubMed Central: PMC6145226].

42. Abel MH, Ystrom E, Caspersen IH, Meltzer HM, Aase H, Torheim $\mathrm{LE}$, et al. Maternal iodine intake and offspring attentiondeficit/hyperactivity disorder: Results from a large prospective Cohort study. Nutrients. 2017;9(11). doi: 10.3390/nu9111239. [PubMed: 29137191]. [PubMed Central: PMC5707711].

43. Tauman R, Levine A, Avni H, Nehama H, Greenfeld M, Sivan Y. Coexistence of sleep and feeding disturbances in young children. Pediatrics 2011;127(3):e615-21. doi: 10.1542/peds.2010-2309. [PubMed: 21357344].

44. Tauman R, Avni H, Drori-Asayag A, Nehama H, Greenfeld M, Leitner Y. Sensory profile in infants and toddlers with behavioral insomnia and/or feeding disorders. Sleep Med. 2017;32:83-6. doi: 10.1016/j.sleep.2016.12.009. [PubMed: 28366346].

45. Shani-Adir A, Rozenman D, Kessel A, Engel-Yeger B. The relationship between sensory hypersensitivity and sleep quality of children with atopic dermatitis. Pediatr Dermatol. 2009;26(2):143-9. doi: 10.1111/j.1525-1470.2009.00904.x. [PubMed: 19419459]. 